\title{
Perceptions of a Rape Prevention Program by Fraternity Men and Male Student Athletes: Powerful Effects and Implications for Changing Behavior
}

\author{
John D. Foubert \\ Edwin A. Cowell
}

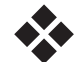

The purpose of this qualitative inquiry was to determine fraternity men and student athletes' perceptions of a commonly used rape-prevention program. Participants saw "The Men's Program" and then participated in 60-90 minute focus groups assessing whether their attitudes and behavior would change, what about the program led to that change, and what improvements they recommended. After seeing this peer education program that included a video describing a male-on-male rape experience, participants reported increased empathy with rape survivors, an increased ability to help survivors recover, and several areas where they planned to change their behavior. Areas of planned change included behavior in intimate encounters and responding to survivors by believing their stories. Participants suggested a stronger emphasis on alcohol and
\end{abstract}

John D. Foubert, Ph.D., is an assistant professor and Edwin A. Cowell is the area director of Residence Life at The College of William and Mary.

The first author wishes to acknowledge that this research was made possible by an ACPA Emerging Scholar Research Grant funded by Josten's Inc. and by a William and Mary Faculty Summer Research Grant generously funded by Ms. Suzann Matthews. 
consent and a less intense plea to help change social norms. Several implications for student affairs generalists and rape prevention programmers are discussed.

Research has consistently shown alarmingly high rates of college women reporting incidents of rape and other forms of sexual assault, with prevalence of victimization consistently reported between 20-25\% among college women (Douglas et al., 1997; Koss, Gidycz, \& Wisniewski, 1987; Tjaden \& Thoennes, 1998). These consistently daunting statistics indicate a serious problem for student affairs administrators who seek to insure the safety of their students as they pursue personal growth and academic excellence.

Several theories of attitude and behavior change have been applied to the complex problem of ending men's violence against women. Two of the more promising and applicable theories are belief system theory (Grube, Mayton, \& Ball-Rokeach, 1994) and the elaboration likelihood model (ELM) (Petty \& Cacioppo, 1986). Belief system theory suggests that to produce lasting attitude change, interventions must be designed to maintain people's existing self-conceptions (Grube et al., 1994). Yet, nearly all interventions reported in the literature assume male program participants to be potential rapists (Lonsway, 1996). Yet even convicted rapists rarely define their behavior as "rape" (Koss et al., 1987; Peterson \& Franzese, 1987). Thus their probability of success seems low according to this theory. The ELM suggests that lasting attitude change is more probable when participants are motivated to hear the message, are able to understand it, and deem the persuasive material to be relevant to them. Thus, in order for rape prevention interventions to be successful, proponents of the ELM would argue that men must consider rape prevention interventions personally relevant.

Several studies of interventions designed to address sexual assault have focused on male populations that are at a greater risk for committing sexually aggressive acts, including fraternity men and male student athletes. Both populations have been found to have attitudes that are more supportive of rape than other men (Boeringer, 1999), to be more likely to commit gang rape than other college men (O'Sullivan, 1991), and to be more likely to sexually abuse women 
(Chandler, Dewayne, \& Carroll, 1999; Garrett-Gooding \& Senter, 1987).

A recent meta-analysis of rape prevention programs found that allmale, peer education programs are far more successful than mixed gender programs and those not presented by peers (Brecklin $\&$ Forde, 2001). In addition, as men increase their empathy with survivors, understand rape trauma better and have more aversion to rape, they report less likelihood of raping (Hamilton \& Yee, 1990; Schewe \& O'Donohue, 1993). Empathy with survivors has been shown to be particularly important. Specifically, research has shown that men who have no proclivity to rape have greater empathy toward survivors, while men who indicate some degree of rape proclivity have lower empathy toward survivors (Osland, Fitch, \& Willis, 1996).

Many approaches have attempted to increase men's empathy toward rape survivors, with strikingly similar findings. At least nine studies have been published that assess the effects of an empathy-based intervention on men's attitudes toward rape and/or their behavioral intent to rape. Six of these studies (Foubert, 2000; Foubert \& Marriott, 1997; Foubert \& McEwen, 1998; Gilbert, Heesacker, \& Gannon, 1991; Lee, 1987; Schewe \& O'Donohue, 1993) have assessed the impact of describing a male as a survivor of a male-on-male rape. Three studies (Berg, 1993; Berg, Lonsway, \& Fitzgerald, 1999; Ellis, O'Sullivan, \& Sowards, 1992) have assessed the impact of describing a female as a survivor of a male-on-female rape. All six studies depicting a man as a survivor led to significant declines in men's likelihood of raping and/or their rape myth acceptance or other similar attitudes. In stark contrast, all of the studies evaluating the impact of describing a woman's experience as a survivor increased men's rape myth acceptance, and in the case of Berg (1993), also increased men's likelihood of sexual aggression. Authors suggest that describing male-on-female rape may reinforce men's beliefs about rape and/or may even be arousing to male research participants (Berg, 1993; Berg, Lonsway, \& Fitzgerald, 1999; Ellis, O'Sullivan, \& Sowards, 1992). Together, these findings point to the need for men to understand rape through hearing about a male-on-male rape situation in order to develop the empathy with rape survivors that is necessary for lower likelihood of raping and lower rape myth acceptance. 
The vast majority of available research on rape prevention is quantitative in nature. Quantitative research allows the benefits of generalizability, prediction, and making causal explanations (Borg \& Gall, 1989). More recently, a limited number of studies have been published that have used qualitative inquiry, offering the benefit of understanding programmatic impact from the personal, descriptive perspectives of target audiences. For example, extended interviews with college men suggest that focusing on a message that implicates men as potential rapists through discussion of respecting a woman's "no," and not engaging in intercourse when drunk are often rejected by men. While these lessons are obviously important for men to learn, when used as the primary emphasis of programmatic interventions, men reject the approach because they do not see themselves as rapists and therefore see the information presented as irrelevant to them personally (Scheel, Johnson, Schneider, \& Smith, 2001). Instead, based on the same interviews and a review of the literature, researchers suggest emphasizing the role of men to help and emotionally support survivors. This approach is seen as having the potential to also encourage men to examine ways to prevent rape and sexual assault from happening again.

Schewe (2002) reports that The Men's Program (Foubert, 2003) is the only program that has ever been shown to produce clear, long-term change in men. This all-male rape prevention, victim empathy-based, one-hour peer education program titled "How to Help a Sexual Assault Survivor: What Men Can Do" has been shown by quantitative research to significantly lower men's rape myth acceptance and their likelihood of raping-effects shown to last for an entire academic year (Foubert \& McEwen, 1998; Foubert, 2000). In an additional qualitative study describing how men understand and make meaning of their experience with this program, Foubert and LaVoy (2000) found that more than half of the fraternity men in their study reported that their attitudes and/or behavior changed in the direction of increased awareness or sensitivity to rape seven months after program participation. Those who believed the program did not change their attitudes or behavior often reported that they already agreed with the program's message. 
The part of the program most frequently mentioned to have impacted men in Foubert and Lavoy's (2000) study was a videotape in which a male police officer describes a situation in which another male officer is raped by two men. Other parts of the program that were mentioned included the general way the program raised awareness and a section that described how to help a sexual assault survivor. The increased awareness and sensitivity to rape reported in this inductive analysis confirms the increased awareness and sensitivity toward rape suggested by the quantitative measures (Foubert \& McEwen, 1998; Foubert, 2000), but leaves open many new questions about what attitudes and behaviors had changed and what about the program led to those changes. The present study sought to explore the impact of The Men's Program more deeply and with an additional target population. According to Patton (1990), focus groups allow the researcher to explore earlier quantitative findings by uncovering the ways in which participants find programs meaningful in depth and using their own words. To that end, the present investigation used focus groups to explore the deeper meaning and impact of The Men's Program on fraternity men and male student athletes. The following research questions guided this study:

1. Which attitudes are impacted by participating in The Men's Program and what about the program changes these attitudes?

2. What, if any, behaviors are impacted by The Men's Program and what about the program changes these behaviors?

3. Are there any modifications that could be made to the program that would make it more effective in changing attitudes and behavior?

\section{Method}

\section{Participants}

Participants for this study were full-time traditional age undergraduate male students enrolled at a public, southeastern university with an enrollment of approximately 5,000 undergraduate students. Participants included 12 fraternity men and 14 student athletes, who 
were divided evenly into two focus groups of six fraternity men and two focus groups of seven student athletes. Participants were either current members of a varsity athletic team including baseball, football, and gymnastics or were members of one of five participating fraternities.

\section{Procedure}

Participants were encouraged to attend through emails sent directly to purposive samples (Krueger, 1998) from each athletic team and each fraternity on campus and announcements at meetings made by fraternity men and athletes to their peers. A prepaid long-distance phone card with 600 minutes or a $\$ 25$ campus bookstore gift certificate was offered as an incentive.

Participants attended a one-hour presentation of The Men's Program (Foubert, 2003) by thoroughly trained and experienced peer educators, immediately followed by a 60-90 minute focus group session. The Men's Program, also called "How to Help a Sexual Assault Survivor: What Men Can Do," started by setting a nonconfrontational tone and noting that they would learn how they can make a difference with women who come to them for help minutes or even years after being sexually assaulted. After disclaimers, an overview, and review of rape definitions, presenters said they would see a videotape describing a rape situation. This tape described a male police officer being raped by two men depicted as violent, known previously to the officer, and heterosexual.

At the conclusion of the video, presenters noted that as with most male-on-male rape, the video they just watched depicted two presumably heterosexual men using rape and battery to exert power and control over the survivor. Presenters then drew parallels from the male police officer's experiences to common experiences of female rape survivors. Participants were then taught basic skills on how to help a woman recover from rape. Next, presenters discussed how to define consent in intimate encounters and how to intervene as a bystander to help change social norms that condone rape. After answering questions, participants were reminded of the prevalence of rape and the necessity for everyone to work together to end men's violence against 
women. A complete description of this program can be found in Foubert (2003).

Following the guidelines of Krueger (1998), focus group sessions were conducted with a facilitator, a note-taker, and an audio recorder to capture participants' comments and to facilitate optimal extraction of relevant themes. Prepared questions guided the discussion to assess participants' perceptions of the program, how it affected their attitudes, how it might change their behavior, what about the program led to any change, how being an athlete or fraternity member affected their perceptions, and how they would improve the program. Verbatim transcripts were made of each focus group, using individual recorder's notes to insure accuracy of participant's comments and to capture deeper interpretations of participants' feedback including nonverbal responses. Focus group transcripts were read independently by two readers who then discussed what themes they were seeing. After reading the transcripts several times and coding responses, themes were extracted based on the frequency, extensiveness, and intensity of participant comments (Kreuger, 1998). Researchers determined a theme to be present when each of us uncovered the theme in all four focus groups. One exception was made in a case where three of four focus groups contained the theme, which was not contradicted by the fourth group.

\section{Results and Discussion}

Responses from focus group participants clustered around six general themes. Participants reported that the powerful video shown during the program was its most influential component. They also reported that after seeing the program, they were much more able to help a survivor of sexual assault than they had been before. Participants also pointed to other sections of the program that were influential to them, suggested what changes they anticipated making in their own behavior, made suggestions for changes in the program, and discussed the manner in which they believed the program related to their role as a fraternity man or student athlete.

One of the most interesting findings of this study was that the responses of student athletes and fraternity men were nearly identical. 
In five out of the six themes extracted in this study, all focus groups contained comments that are represented by the theme. The only exception was a theme mentioning additional influential aspects of the program, where one of the fraternity focus groups mentioned fewer parts of the program. Within the themes, some minor differences emerged between athletes and fraternity men with regard to suggested program changes. Below, each theme is discussed along with quotes that are most characteristic of the particular theme.

\section{Powerful Video}

The most frequent, extensive, and intense theme in all focus groups was that the videotape describing a male police officer's experience being raped by two men was the most powerful aspect of the program. Participants reported that seeing a video describing a male-on-male rape taught them what rape feels like in a way that a male-on-female scenario could not have done, and that it taught them in a unique way about the after-effects of rape. As one fraternity man put it:

To get a perspective of how a guy would feel going through something like this helps you understand some of the things a female has to deal with. ... Usually, there is a girl who gets up and talks about her experience and they expect you to identify or understand what she has gone through. The fact that this program was graphic . . . it just hits you in the face, I mean you can't really not think about it based on the way it was presented.

Another fraternity man added:

It (the video) really drove it home, the whole thing, he lost his gun, that he was completely helpless. Where before we were like, just ... hit him upside the head, something like that . . . it was a great way of making us feel like a woman would have, we could perceive how a woman would feel. One hundred percent change. Instead of saying why didn't you wear something else, it's more of a, I'm sorry, I'm here for you.

An athlete noted the effectiveness of depicting a police officer as the victim:

I think when you see the cop ... the strongest of male figures possible, I think it hit home that if it can happen to that person, 
someone who is armed and well trained, and it still happens to them, it can happen to anybody; it shows the complete helplessness a person can find themselves in.

\section{More Able to Help a Survivor}

Participants consistently reported that they were more able to help a survivor after having participated in the program. Athletes and fraternity men reported a greater sympathy toward survivors, a greater understanding of how to be supportive, and a greater awareness of the need to help the victim regain control. In addition, they reported that the program taught them about what not to do when helping a woman who has been raped. As an athlete put it:

I definitely learned, you know, just about what to do if somebody does come to you in that kind of situation. I mean, I've never been faced with a situation like that before, but if I was, before I don't think I would have known how to deal with it properly. And this really showed you what to do and some things to really avoid.

A fraternity man noted how he learned that more violence is counterproductive:

I think I will change how I respond at first. I have been in this situation a couple of times this year just recently and my first responses were how do I get her in touch with someone who can help her. At the same time, I'm thinking I want to get my baseball bat and go after the guy who did this. But you kind of have to stay focused on helping your friend regain her power and so you have to sort of put your emotions aside.

\section{Other Helpful Aspects of the Program}

Participants in both athlete groups and one of the fraternity groups reported additional program components, beyond the powerful video and the emphasis on helping a survivor, as effective. Both groups of student athletes reported being influenced by statistics mentioned in the program (i.e., 26 women an hour in the United States are sexually assaulted). An athlete group and a fraternity group reinforced that the all-male format was critical in the program's efficacy. An athlete indicated a preference for male peer educators "because that way I feel more like it's men asking me to be aware of this, rather than feeling 
like it's a woman telling me." Others noted that they and their peers would feel uncomfortable asking questions of female presenters and that they were more likely to listen to a male regarding these issues.

\section{Behavior Changes}

Participants in all focus groups identified ways they expected their behavior would change after having seen the program. Participants indicated that they would be more aware of their own behavior in intimate situations. One athlete noted that he learned "cooperation does not necessarily mean consent." He continued by expressing that he discovered that "as a guy you might not realize you're doing something that makes her feel uncomfortable. You don't feel like you're doing anything threatening, but she feels threatened and is cooperating for that reason." With this reflection, the student indicated that he would think twice in future situations, and ask for clarification rather than assume that consent is present. Other participants expressed similar effects from the program, stating that they would likely be more aware of their own behavior in intimate situations, and cited the video as being the central program component of their proposed behavior and attitude change. Another athlete noted the program helped him by:

Just knowing the basic laws, and being more sensitive to those, like cooperation isn't consent. That's like, at first that can be really, really hard to grasp, and the program spelled it out, spelled it out clear. Helped make it more believable, I guess.

Several others in the group nodded in agreement with this point. Urging the program to be presented more widely, a fraternity man stated:

Like I don't know what the statistics are for the aggressors, like you say 1 in 4 people have been raped, but I would be interested in like, 1 of how many would be the aggressor. I think that if you do this program on a larger scale it would bring that number down, because people would check their behavior.

Participants in one fraternity and one athlete focus group stated that they were now more likely to believe a survivor. Participants elaborated that if they faced a situation where they knew a survivor of sexual assault, they would be more likely to listen and attend to the needs of 
the survivor, rather than respond to their own tendency of wanting to bring physical harm to the alleged perpetrator, or wanting to "fix" things for the survivor. An athlete noted, and all in his focus group nodded in agreement, "It changed, like before I think would've been prone to ask the questions like, 'did you invoke it or did you kiss him?' But now I know that I shouldn't ask that, that I should generally believe her and, you know, try to comfort her." Another athlete added:

Yeah, I feel like it's normally assumed she's wrong until there's overwhelming evidence that it's true. And for me it's an easy thing right now just assume she's right, it's just better that way. And I don't even feel that that's a hard assumption for me to make. . . . I see now that it's better to assume she's telling the truth.

However, if a friend of theirs was the alleged perpetrator and the survivor was not a friend, many said that they would believe and support their friend. A fraternity man pointed out that:

Most of the time if it's not a guy that you know very personally then I would say that I would believe the victim. But there's that grey area where if a girl comes up and accuses a friend of mine, sure I'm not going to dismiss her as being wrong or lying but I'm going to talk to my friend and see what the deal is before I make any opinion. And I know that would be hard for her but it's a fact of life in human relationships.

Both athletes and fraternity men demonstrated a greater self-awareness concerning their own behavior and how their attitudes may indeed perpetuate rape myths. Such awareness was demonstrated by participants' acknowledgement of particular language or jokes they either used themselves, or frequently heard expressed by their male peers. While such jokes may seem innocuous to some, finding ways to curtail the use of such jokes is important given that the enjoyment of sexist humor by men correlates significantly with rape myth acceptance, adversarial sexual beliefs, acceptance of interpersonal violence, likelihood to force sex, psychological aggression, physical aggression, and sexual aggression (Ryan \& Kanjorski, 1998). Based on the participants' description of a deeper awareness and understanding of rape trauma, they indicated that such expressions were not appropriate and that they would likely be more conscious of such expressions. One athlete noted, "I think I will probably make a conscious effort, about 
the comments about rape and the sexist comments too, to watch what I say around people in an effort not to perpetuate the attitude that women are somehow inferior." Similarly, a fraternity man reflected on his prior comments about rape and reported:

I know I've come out of exams and someone will ask me how I did and I'll say that exam just bent me over and had its way. Making you think about saying those little things and what you're really saying. Instead of just saying it in jest; thinking about what's actually coming out of your mouth when you say that.

\section{Suggested Changes}

A fifth theme involved suggestions to improve the program, including adding an emphasis on less violent, more unclear forms of rape and sexual assault. One of the fraternity groups strongly emphasized the need for the program to deal more directly with alcohol and consent. An athlete group suggested that when encouraging men to address societal issues involved in ending rape that the language of the program move from a "lofty" posture of "changing social norms" to "doing your part." One athlete suggested:

Rather than, you know, saying 'go out and change,' just make sure that you do your part. As far as, you know, just respect and have sympathy for rape victims. Just really respect the whole idea of rape. You know, don't joke about it. Just emphasize doing your part, not necessarily going out and changing everybody else. You know, if everybody does their part it will be slowly changed.

In one of the fraternity focus groups, an extensive discussion pointed to the need to focus more on the intersection between alcohol and consent. As one fraternity man noted:

I thought they touched on the real obvious, it was great but it was an obvious case of rape. . . But from a fraternity standpoint, there's a lot of cases where both people are drunk or one of them is drunk and there's all that grey area in there. My only criticism of this program would have been to see a little more development about that. Because that's statistically more frequent than the others. 
Another fraternity man added:

We definitely, I think, take responsibility for our house. If you have a party at your house you don't want anything to go wrong. At the same time you want everybody to have a good time. You've got to balance things like that. So, if two people are going to go upstairs and go hookup do you ask them, do you pull the girl aside and ask them, "are you sure?" It doesn't really necessarily seem appropriate but maybe it is, I don't know but that's an extreme grey area that we don't really know how to handle. . . . The program was great but I don't have any answers for those kind of questions. ...

\section{Relation of Program to Role as Fraternity Man or Student Athlete}

Several interesting points emerged from the discussions regarding how their group membership (athletic team or fraternity) impacted their reaction to and the relevance of the program. In both athletic groups and one fraternity group, the first person to respond to the question asking if the program related to them as fraternity members/athletes responded that it did not, such as one athlete who said "I don't really think so, I don't see why it would, I mean if I didn't play a sport, I would not look at it any differently I don't think." Then, the rest of the group countered this perspective by mentioning ways they believed the program and/or the topic of the program related to them as athletes or fraternity men. The great commonality in their responses was that they saw the issue of sexual assault as relevant to their physical spaces. Fraternities emphasized how they see incidents of sexual assault in their houses. Athletes mentioned how they hear rape jokes and stories about sexual assault in their locker rooms.

Both fraternity men and student athletes commented that doing programs with their particular target audience in mind would be more beneficial, student athlete participants seem to be more individualistic about the program's impact and noted that to them, the issue of sexual assault had less to do with being part of a team. However, student athlete participants did acknowledge that their status as a student athlete presented different obstacles for them. For example, one student commented that being a student athlete, people have a tendency to label you and that you are sometimes more visible on campus by virtue of your participation in varsity athletics. On the other hand, fra- 
ternity group participants seem to have a more difficult time separating themselves from their group membership.

Both athletes and fraternity men agreed that they hear about rape, from both sides, more frequently than other college men. They also agreed that the program they saw should be presented to their entire chapter or team rather than just to the few members who attended the sessions for the present study. One athlete noted:

It's like locker rooms . . . a lot of the stories you hear, I know that I've heard, could be or would be important, considered sexual assault. Like, a lot of times you can think about it, just be like I want to tell the guy they're putting themselves in danger and they're also harming the girl in this way. From seeing the video, you can be causing a female to go through that kind of certain anxiety problems or whatever it may be. The program could benefit them.

Commenting on the way fraternity men perceive the issue, a fraternity man noted:

I think just being a member of a fraternity makes it so we at least feel like we are either faced with those situations or hear of those situations more often than other college students. That may not be true but it really makes us feel that way. Since the parties are at our houses and things of that nature I guess we feel like it's a lot more visible to us.

Another fraternity man suggested it would be best for entire chapters to see the program instead of just a few guys in each house:

I almost think that to present it to small groups would not have the same impact than if you sat down with your entire fraternity and showed the film. Like not that the message would be any stronger but it would be more uniform across the board. Like everybody would have that feeling. I mean like when the program ended there was sense of a really somber mood, and afterwards, everybody was like wow, you really didn't expect that. I mean we can go back to our organizations and talk about it with our fraternity brothers or start up some discussion, but I don't think it would be as powerful as if you had a group that is going to be together and they all see the same thing and they all have that 
feeling about the message. I just think that feeling would last longer and have much more of a positive impact in general.

\section{Conclusion}

Several implications arise from the findings of this study. First, the comments of the fraternity men and student athletes confirm and extend earlier quantitative findings that the program used is effective in changing men's likelihood of raping and their attitudes toward the subject of rape. Most importantly, participants conveyed the strong message that seeing a video describing a male-on-male rape experience was essential for their understanding of what rape feels like. In addition, the fact that the responses from athletes mirrored the responses from fraternity men suggests that earlier findings on the effectiveness of The Men's Program with fraternities may extend to athletic teams. Future research should be done to clarify this point.

One caution that should be considered in describing a male-on-male rape experience is to be careful not to perpetuate any preexisting homophobic attitudes among audience members regarding male-onmale contact. As with most male-on-male rape situations, the video used for this program uses a situation in which presumably heterosexual men are the perpetrators. This point is emphasized by presenters after the conclusion of the video to directly confront the primary way homophobia and rape intersect- the mistaken assumption that if a man rapes a man that the perpetrator must therefore be homosexual. Thus, describing a male-on-male rape experience in the context used in this program can help dismantle homophobic attitudes among audience members in addition to building empathy for rape survivors. Program participants were unequivocal about the powerful impact the video had on them to help them understand rape, and noted specific changes in their attitudes and how they believed they would act in the future as a direct result. Thus, strong support was offered for this method, particularly when presented in an all-male, peer education format that emphasizes helping survivors and does not come across to men as blaming them for the problem of rape.

Another important implication of this study involves the comments of one of the fraternity groups regarding alcohol and consent. Clearly, for 
some men, it will be necessary for programmatic efforts including this one to more thoroughly process issues of alcohol and consent. This issue is salient, particularly for fraternity men, with regard to sexual assault. Research has shown that $75 \%$ of men and $55 \%$ of women involved in a rape situation were either drinking alcohol or using other drugs prior to the incident (Koss, Gidycz, \& Wisniewski, 1987). In addition, fraternity men use drugs or alcohol to obtain sex from women more frequently than other men (Boeringer, Shehan, \& Akers, 1991). Alcohol consumption on the part of both parties in a sexual encounter has been defined as an important factor that makes highrisk men more likely to ignore women's physical and verbal requests to stop sexually aggressive behavior. Specifically, when men defined as sexually aggressive hear of intimate situations involving alcohol, they are more likely to discount women's protests to stop when alcohol is present than when it is not. Men who were not defined as sexually aggressive were both less likely to ignore women's requests to stop and were not affected in this judgment by the presence of alcohol (Bernat, Calhoun, \& Stolp, 1998). Thus, it seems all the more important that programs that seek to change men's sexually coercive behavior work directly to dismantle the disposition of sexually aggressive men to ignore women's protests when alcohol is present. While the program studied presently mentioned alcohol issues briefly, it seems necessary to include a more extensive focus on alcohol in this and other sexual assault programs to be more effective. Finding an effective technique for accomplishing this objective seems to be the greatest challenge in rape prevention programming today, and may well be the key to producing documented reductions in sexual assault.

Several limitations must be considered when interpreting the results of this study. One limitation of the present study is that the focus groups were conducted immediately after participants saw the program. Therefore, the information was fresh in their mind and the experience of attending the program was still in their short-term memory. Given that the focus groups occurred immediately after program participation, the present study only measures the potential for sustained change in attitudes and behavior, not any sort of long-term change itself. Particularly with measuring any behavior change, longterm follow-up is the best way to determine whether participants do anything differently as a result of program participation. A five-month 
follow-up was conducted with participants in the present study, and it will be reported on in a subsequent article to lend credence to and expand upon the present findings (Foubert \& Perry, 2004).

In addition, the present study used a small number of participants who all attended the same university. While using small numbers of participants allows for greater depth of description, it is also limiting with regard to confident generalization. Given that all participants attended the same university, cultural aspects of the institution could have influenced the findings. Therefore, one must be careful not to generalize these findings in the absence of further research on other populations with a wider variety of qualitative and quantitative methods. Ultimately, the qualitative information collected in this study helps flesh out prior quantitative findings and adds depth of description to what is known about the program's effects. However, generalization of the reported perceptions should only be made with further research.

As student affairs administrators seek to understand how to prevent rape on college campuses, programs that describe male-on-male rape experiences offer promise when processed carefully. In addition, the present study suggests that teaching men how to help women recover from rape can lead to powerful changes in how they say they would respond to survivors. Furthermore, tailoring our rape prevention program messages to the unique characteristics of selected target audiences seems appropriate, particularly when it comes to alcohol-related sexual assault. The present study suggests the importance of identifying new and effective strategies to address alcohol-related sexual assault and that such approaches need to be integrated into our rape prevention efforts. Ultimately, the present study helps us identify key elements to include in our programmatic efforts as we seek to decrease incidents of sexual assault on our campuses.

\section{References}

Berg, D. R. (1993). The use of rape-specific empathy induction on rape education for college men: A theoretical and empirical examination. Unpublished Master's Thesis. University of Illinois, UrbanaChampaign. 
Berg, D. R., Lonsway, K. A., \& Fitzgerald, L. F. (1999). Rape prevention education for men: The effectiveness of empathy-induction techniques. Journal of College Student Development, 40 (3), 219-234.

Bernat, J. A., Calhoun, K. S., \& Stolp, S. (1998). Sexually aggressive men's responses to a date rape analogue: Alcohol as a disinhibiting cue. Journal of Sex Research, 35 (4), 341-348.

Boeringer, S. B. (1999). Associations of rape-supportive attitudes with fraternity and athletic participation. Violence Against Women, 5 (1), 81-90.

Boeringer, S. B., Shehan, C. L., \& Akers, R. L. (1991). Social contexts and social learning in sexual coercion and aggression: Assessing the contribution of fraternity membership. Family Relations, 40, $58-64$.

Borg, W. R., \& Gall, M. D. (1989). Educational research: An introduction. New York: Longman.

Brecklin, L. R., \& Forde, D. R. (2001). A meta-analysis of rape education programs. Violence and Victims, 16, 303-321.

Chandler, S. B., Dewayne, J. J., \& Carroll, P. S. (1999). Abusive behaviors of college athletes. College Student Journal, 33 (4), 638-645.

Douglas, K. A., Collins, J. L., Warren, C., Kann, L. Gold, R., Clayton, S., Ross, J. G., \& Kolbe, L. J. (1997). Results from the 1995 national college health risk behavior survey. Journal of American College Health, 46, 55-66.

Ellis, A. L., O'Sullivan, C. S., \& Sowards, B. A. (1992). The impact of contemplated exposure to a survivor of rape on attitudes toward rape. Journal of Applied Social Psychology, 22, 889-895.

Foubert, J. D. (2003). The men's program: How to successfully lower men's likelihood of raping ( ${ }^{\text {red. }}$ ). Holmes Beach, FL: Learning Publications.

Foubert, J. D. (2000). The longitudinal effects of a rape-prevention program on fraternity men's attitudes, behavioral intent, and behavior. The Journal of American College Health, 48, 158-163.

Foubert, J. D., \& LaVoy, S. L. (2000). A qualitative assessment of "The Men's Program:" The impact of a rape prevention program on fraternity men. NASPA Journal, 38, 18-30.

Foubert, J. D., \& Marriott, K. A. (1997). Effects of a sexual assault peer education program on men's belief in rape myths. Sex Roles, 36, 257-266.

Foubert, J. D., \& McEwen, M. K. (1998). An all-male rape prevention peer education program: Decreasing fraternity men's behav- 
ioral intent to rape. Journal of College Student Development, 39, $548-556$.

Foubert, J. D., \& Perry, B. C. (2004). Creating lasting attitude and behavior change in fraternity men and male student athletes: The qualitative impact of an empathy based rape prevention program. Manuscript submitted for publication.

Garrett-Gooding, J. \& Senter, R. (1987). Attitudes and acts of sexual aggression on a university campus. Sociological Inquiry, 59, 348-371.

Gilbert, B. J., Heesacker, M., \& Gannon, L. J. (1991). Changing the sexual aggression-supportive attitudes of men: A psychoeducational intervention. Journal of Counseling Psychology, 38, 197-203.

Grube, J. W., Mayton, D. M, \& Ball-Rokeach, S. J. (1994). Inducing change in values, attitudes, and behaviors: Belief system theory and the method of value self-confrontation. Journal of Social Issues, 50, 153-173.

Hamilton, M., \& Yee, J. (1990). Rape knowledge and propensity to rape. Journal of Research in Personality, 24, 111-122.

Koss, M. P., Gidycz, C. A., \& Wisniewski, N. (1987). The scope of rape: Incidence and prevalence of sexual aggression and victimization in a national sample of higher education students. Journal of Consulting and Clinical Psychology, 55, 162-170.

Krueger, R. A. (1998). Analyzing and reporting focus group results. Thousand Oaks, CA: Sage Publications.

Lee, L. A. (1987). Rape prevention: Experiential training for men. Journal of Counseling and Development, 66, 100-101.

Lonsway, K. A. (1996). Preventing acquaintance rape through education: What do we know? Psychology of Women Quarterly, 20, 229-265.

Osland, J. A., Fitch, M., \& Willis, E. E. (1996). Likelihood to rape in college males. Sex Roles, 35 (3-4), 171-183.

O'Sullivan, C. (1991). Acquaintance gang rape on campus. In A. Parrot \& L. Bechhofer (Eds.), Acquaintance rape: The hidden crime (pp. 140-156). New York: John Wiley \& Sons.

Patton, M. Q. (1990). Qualitative evaluation and research methods. Newbury Park, CA: Sage Publications.

Peterson, S. A., \& Franzese, B. (1987). Correlates of college men's sexual abuse of women. Journal of College Student Personnel, 28, 223-228. 
Petty, R. E. \& Cacioppo, J. T. (1986). Communication and persuasion: Central and peripheral routes to attitude change. New York: Springer-Verlag.

Ryan, K. M., \& Kanjorski, J. (1998). The enjoyment of sexist humor, rape attitudes, and relationship aggression in college students. Sex Roles, 38 (9/10), 743-756.

Scheel, E. D., Johnson, E. J., Schneider, M., \& Smith, B. (2001). Making rape education meaningful for men: The case for eliminating the emphasis on men as perpetrators, protectors, or victims. Sociological Practice: A Journal of Clinical and Applied Sociology, 3 (4), 257-278.

Schewe, P. A. (2002). Guidelines for developing rape prevention and risk reduction interventions. In P. A. Schewe (Ed.), Preventing violence in relationships: Interventions across the life span (pp. 107-136). Washington, DC: American Psychological Association.

Schewe, P., \& O'Donohue, W. (1993). Rape prevention: Methodological problems and new directions. Clinical Psychology Review, 13, 667-682.

Tjaden, P., \& Thoennes, N. (1998). Prevalence, incidence, and consequences of violence against women: Findings from the national violence against women survey, 2-5. Research in Brief. Washington, DC: National Institute of Justice, US Department of Justice. 